\title{
DECISION MAKING UNDER UNCERTAINTY IN COASTAL ZONE MANAGEMENT
}

\author{
A. Félix, A. Baquerizo, J. M. Santiago and M. A. Losada ${ }^{1}$
}

\begin{abstract}
We analyze decision making under uncertainty in a search for an integral management solution for Playa Granada in the Guadalfeo River Delta (Granada, Spain), where the construction of a dam in the river basin is causing severe erosion. Different management strategies are considered. For each of them the assessment of the uncertainty in the accomplishment of the management targets is done with a methodology that takes into account the coupled action of atmosphere, ocean, and land agents and their intrinsic stochastic character. This information is used to infer the joint distribution function of three criteria that represent the economic benefit of different interest groups. A stochastic multicriteria decision method that accounts for the uncertainty in the performances of alternatives and also in decision makers preferences, is used to rank strategies according to their effectiveness in an informed and transparent process.

Keywords: Stochastic multi-criteria analysis, integrated coastal zone management, decision making under uncertainty
\end{abstract}

\section{INTRODUCTION}

The industrial development of the last two centuries and the growth of beach tourism have favored an irrational occupation of the coast that is usually justified for economic reasons. However, such tourism also brings high environmental and economic costs (Stynes, 1997). Furthermore, the natural disasters of the last decade made evident that the soaring population and the concentration of economic activities in the nearest strip of the seashore increase the risk to human lives and to goods and services, and is a potential source of social conflicts (Santiago, 2006).

Faced with this situation, environmentalist groups demand the preservation of wild zones and the restoration of damaged ones. Against them, industry supporters tout tourism's economic benefits. In between, there is a wide range of intermediate possible positions that may benefit or prejudice certain interest groups. The integral management of the coastal zone (ICZM) is therefore an environmental need and a social demand (Losada, 2012).

In the context of coastal management, decisions makers usually have to propose strategies and analyze their performance on different time scales in terms of economic, social and environmental criteria. The use of public funds and the involvement of communal goods requires not only an informed decision making (DM) but also that the process be as transparent as possible.

The stochastic nature of the system is an additional drawback in the DM process, namely, the assessment of the intrinsic uncertainty that is mainly associated to the stochastic character that climatic agents introduce in the physical processes, and to the uncertainty in the course of economic development.

Félix et al. (2012) proposed a methodology for the integral management of a coastal stretch and to make decisions under uncertainty in a transparent process taking into account the stochastic character of the forcing agents and the physical and socio-economic processes. We applied their model to Playa Granada in the Guadalfeo river delta (Granada, Spain), a coastal stretch that, since the construction of a reservoir in the river basin which regulatory activities started in 2005, is suffering a severe erosion problem (Ávila, 2007; Losada et al., 2011), and where a series of non integrated solutions undertaken during the last years have shown to be ineffective.

Three alternatives that represent different management positions are proposed. Among them, one representing an environmentalist attitude, called $A_{0}$; another strategy that is inspired in the current position of the administration and that consists in yearly nourishments of the beach, called $A_{1}$, and finally an alternative denoted by $A_{2}$ that combines the construction of a few groins with a nourishment work and that looks for efficiency in the longer term with a minor impact to the environment.

A traditional risk analysis of the performance of the alternatives is presented first, revealing the convenience of the use of a stochastic multi-criteria method. Alternative $A_{2}$ is shown to be the best one. It is also found that a typical person that prefers this alternative would give almost the same relative importance to all the criteria. The second best is $A_{1}$ and the zero alternative is not considered as admissible.

\footnotetext{
${ }^{1}$ Grupo de Dinámica de Flujos Ambientales, Universidad de Granada, Instituto Interuniversitario de Investigación del Sistema Tierra en Andalucía. Avda. del Mediterráneo s/n. 18006 Granada, Spain
} 
The article is organized as follows. A description of the study zone and the management problem is given first. The application of the methodology to this site is outlined next. Then, the results obtained from the risk analysis and the application of the SMAA are analyzed. Finally, the conclusions derived from the research are presented.

\section{DECISION MAKING UNDER UNCERTAINTY IN THE MANAGEMENT OF PLAYA GRANADA IN THE GUADALFEO RIVER DELTA (GRANADA, SPAIN)}

The Guadalfeo watershed is located in the Spanish Mediterranean coast facing the Alborán Sea (Fig. 1). It has the typical characteristics of semiarid hydrological basins where processes are governed by the scarce pass of low pressure systems over a reduced catchment area. Rainfall temporal distribution is irregular, especially during the dry season (July-September) when torrential rains often occur.

The hydrological regime of the river and historical data suggest that the growth of the Guadalfeo delta is related to extreme events, whose occurrence is significantly smaller than the occurrence of sea states redistributing sediment along the coast during the passage of a storm. Its formation consists therefore in a series of isolated growing 'pulses' alternating with erosion-accumulation periods, as a result of the coupled action of atmosphere, ocean and land agents.

The sedimentary river plain was originally limited to the west by the mountain of El Chaparral and to the east by Cabo de Sacratif. The Motril harbor, built at the beginning of the XXth century on the eastern end of the delta, currently limits its extension. The channelization of the last section of the river at the end of the XIXth century ends with two groins at the mouth.

The most severe deep water wave climate mainly comes from two directions, $105^{\circ}$ and $245^{\circ}$ measured clockwise from $\mathrm{N}$ that arrive obliquely to the shore and contribute to the distribution of the sediment discharged by the river along the coast.

Due to the works done on the river in the last decades, mainly the construction of Rules dam which regulatory activities started in 2005, the shoreline shows severe erosion problems in the area called Playa Granada that were partially solved by punctual nourishment works undertaken with sediment of significantly smaller size than the native and that had a very limited lifespan.

Playa Granada is in the so called Tropical Coast that includes the stretch of the coast of the province of Granada, from Albuñol to Almuñécar (see Fig. 1). This coast has a diverse physical environment that provides support to different productive activities like agriculture -the most important one-, tourism and port operations.

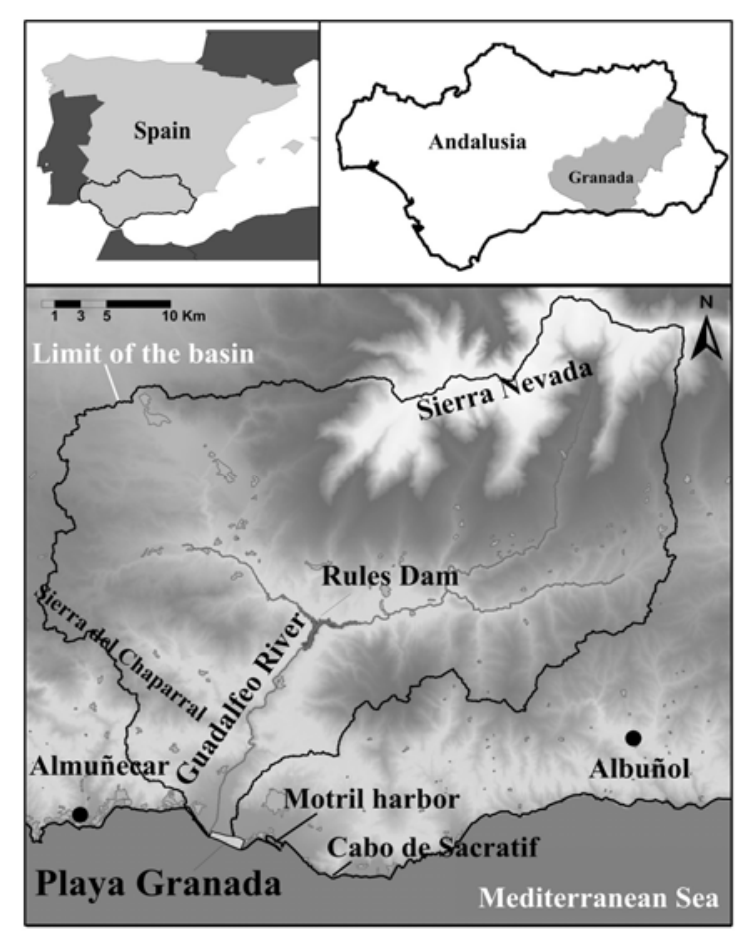

Figure 1. Localization map and aerial view of Costa tropical 
The relevance of touristic sector can be measured in terms of the comparative index of the importance of tourism, an indicator that is calculated in terms of the taxes on economic activities in the touristic sector. From the 100,000 units that correspond to Spain, the participation of the municipalities of the tropical Coast in 2003 was aprox. 373 (La Caixa, 2010) and about 31,3\% of that corresponds to Motril, the closest city to the area of study.

The eastern part of the delta where Playa Granada is located, is occupied by a high standing touristic development. It hosts a seaside resort (golf, hotel, restaurants, etc.) and residential properties that are mainly summer houses. This stretch of the beach is visited by local residents and, during the weekends also by one-day excursionists, especially during the summer.

At the west of this development, in a land reclaimed to a littoral lagoon, several illegal and uncontrolled agricultural settlements have grown. In 2010, the Territorial Plan of the Province of Granada (Junta de Andalucía, 2006) went into force. These settlements will be probably dismantled in the near future in order to restore this natural area.

In the light of these facts, it can be deduced that the area of Playa Granada has a considerable environmental and touristic value which exploitation requires that the beach offers enough dry beach at least during the summer period. Due to the construction of Rules dam it is not likely that the beach recovers during the mild weather conditions, the erosion that it experiences mainly during the winter period. In order to respond to the demand, it is therefore required to undertake works to artificially nourish the beach and to maintain them if necessary.

\section{Methodology for coastal management and decision making under uncertainty}

The methodology proposed by Félix et al. (2012) starts with the definition of the objectives to pursuit within a predefined time interval and the design of strategies aimed at the fulfillment of those goals. A series of indicators that measure the consequences of the fulfillment or not of the management targets and some additional benefits and/or adverse effects are selected for the analysis of the performance of strategies. Due to the random character of the system it is not feasible to predict any of those variables with certitude. Instead, simulations techniques are used to obtain random samples of the variables and to infer their joint probability distribution functions. This information is then processed with a stochastic multi-criteria acceptability analysis method that allows to establish preferences among them. Its application to manage the coastal stretch of Playa Granada is described in detail in the next subsections.

\section{Definition of the management targets and design of strategies}

For the case analyzed here, it was chosen as a management target to offer a minimum beach width of $10 \mathrm{~m}$ all along Playa Granada during a 5 years period. This width is measured from a line that coincides in the western part with the limit of the urban developments, and in the eastern zone with the limit of the agricultural settlements.

Due to the different uses of this area of the coast and to the consequences that a retreat of the shoreline will have, the performance of the alternatives regarding the criteria was assessed at four different stretches called $A$ to $D$. Fig. 2 shows over an aerial photograph, in the considered coordinate system, the reference line used for the verification of the fulfillment of management strategies and the four stretches considered for the analysis.

There are several alternatives to protect beaches against erosion. In this work, the following strategies were considered. In the first one, the so called zero-alternative, $A_{0}$, no action to prevent erosion is taken. Also, a management strategy based on yearly nourishment works, which we designate $A_{1}$, was analyzed. This one is inspired in the management strategy that the former Spanish Ministry of the Environment (Dirección General de Costas, DGC) is carrying out since the beginning of the regulatory activities of Rules Dam in 2005. Another alternative called $A_{2}$ that considers the construction of a series of groins almost perpendicular to the shoreline and an initial nourishment work is also analyzed.

The design of the strategies is aimed at representing different management positions. $A_{0}$ stands for a preservacionist stance that looks for the restoration of the area to its natural situation, regardless of the negative consequences for other interest groups. $A_{1}$ represents the DGC inclination to avoid expensive works and the use of groins that are becoming very unpopular. Finally, $A_{2}$ represents an alternative that looks for efficiency in a longer term than $A_{1}$, causing the minor visual impact with a small number of relatively short groins. At the same time, $A_{2}$ does not interfere with zone $D$ that, although it is right now used as a beach area, it is very likely that it will be recovered as a wetland. 


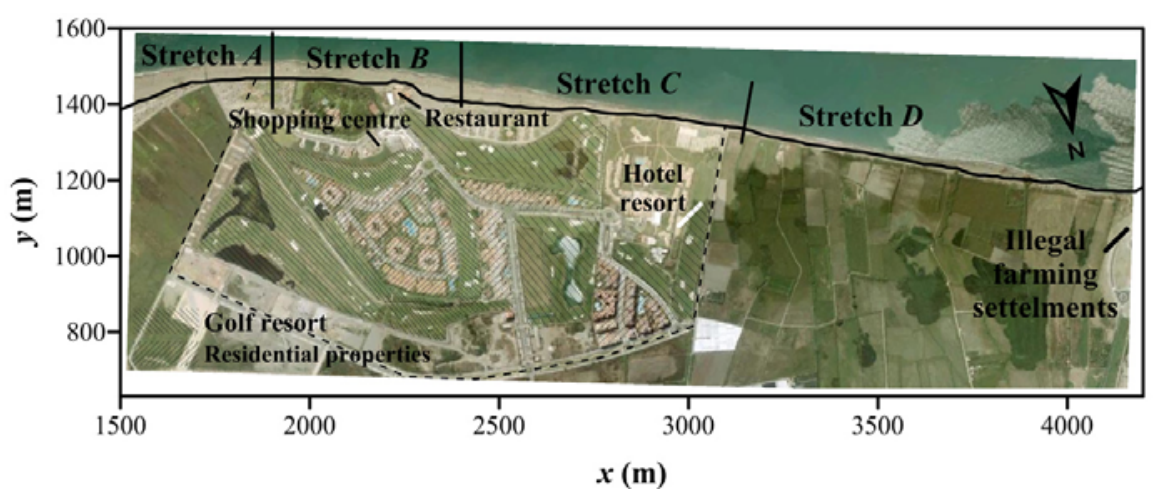

Figure 2. Aerial photograph of August, 15 ${ }^{\text {th }}$, 2007 (Source: Google Earth, 3643'23.77' N and 333'52.41'O) where the reference line that defines the management target and the four stretches considered for the analysis are shown.

For alternative $A_{0}$, it was taken as the initial position of the shoreline the one measured over an aerial photograph taken in August, 15 $5^{\text {th }}, 2007$ (Fig. 2). A1, the management strategy based on soft works, consists in an initial beach nourishment work with sediment size of $D_{50}=1.8 \mathrm{~mm}$ and yearly maintenance actions that consist in the pouring of the sand lost and the reshaping of the shoreline after spring in order to offer a beach in good conditions at the beginning of the summer. It leaves the easternmost part of the shoreline without modifications, as historical information revealed -and numerical calculations confirmed it- that this zone does not suffer erosion problems. It proposes a gain of about $18300 \mathrm{~m}^{2}$ with a shoreline that differs up to $36 \mathrm{~m}$ from the reference (see Fig. 3). The alternative called $A_{2}$ consisted in the construction of 5 groins and the artificial nourishment of the beach with a total gain in dry area of $49020 \mathrm{~m}^{2}$ (see Fig. 4). Groins were designed following the recommendations given in Dean and Dalrymple (2004).

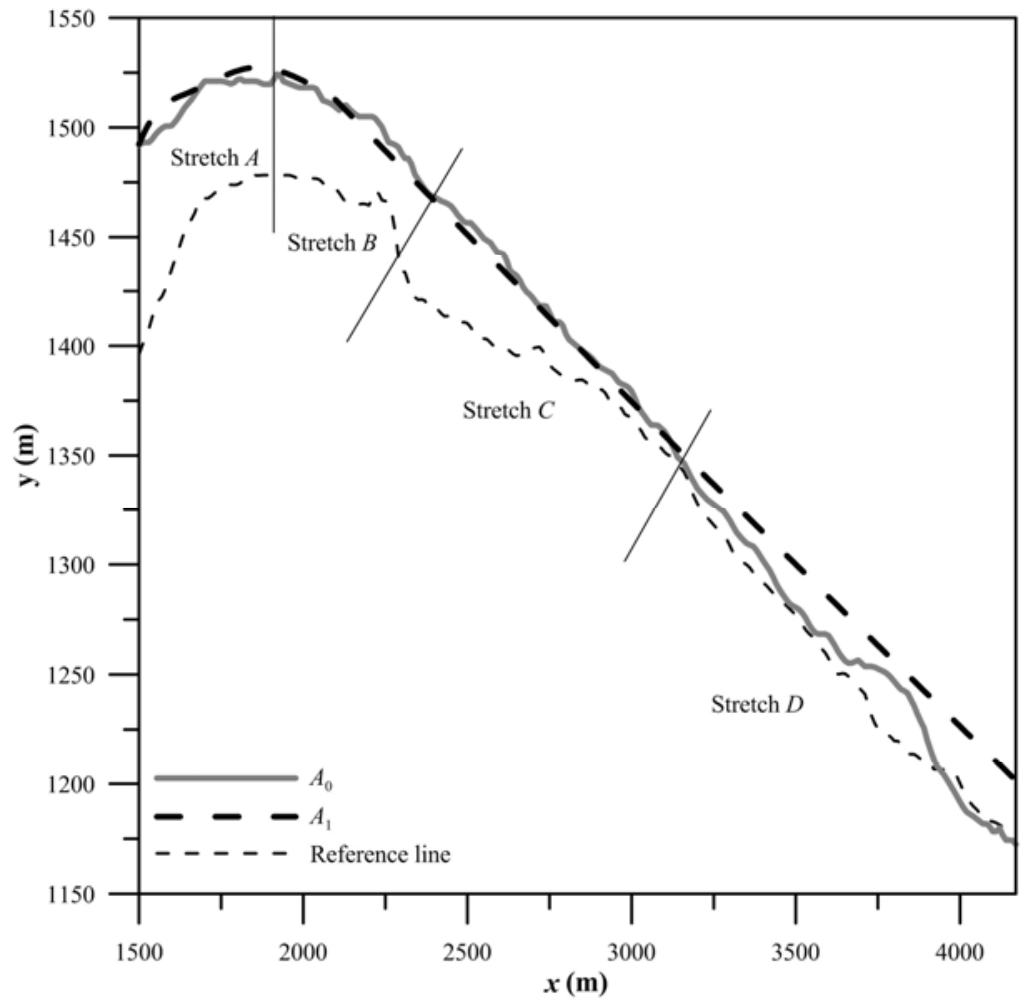

Figure 3. Coordinate system used for the analysis and definition of alternatives $A_{0}$ and $A_{1}$. These shorelines are used as the initial conditions to launch the morphological model. The solid line is the reference curve line for the verification of the fulfillment of the management targets. 


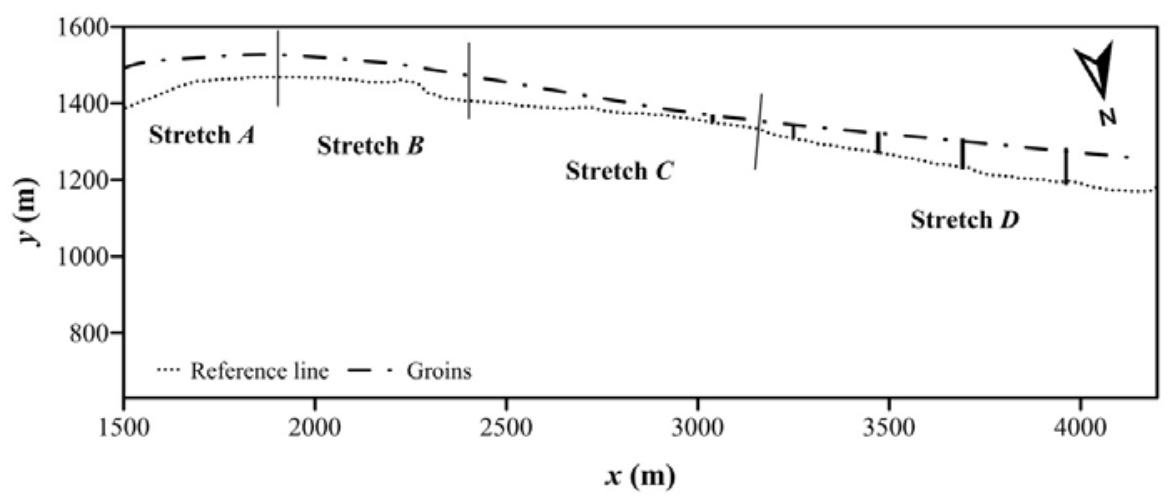

Figure 4. Definition of alternative $A_{2}$

\section{Evaluation of the performance of the alternatives}

The time evolution of the shoreline was analyzed with a one-line model with time dependent boundary conditions (Payo et al., 2002) coupled with a river model that solves Saint-Venant equations for 1D flow and includes a water balance module to include regulatory activities at the dam (Ávila, 2007). For the analysis of the climatic forcing, data of the Mar de Alborán hindcasting point WANA2020013 (Latitude, 36.625; Longitude -3.5) from Puertos del Estado (WANA Project) and daily River discharges at Rules reservoir from 1994 to 2004 (Confederación Hidrográfica del Sur) were used. A more detailed description is given in Ávila (2007) and Losada et al. (2011).

For every strategy, $A_{m}$, the resulting final shoreline position after five years of climatic forcing, $y_{q}(x)$, obtained for simulation $q(q=1, \ldots, Q)$ was estimated following Baquerizo and Losada (2008). Its performance regarding the management target and other benefits was obtained as explained next.

The following random variables (r.v.) were considered:

- $D_{\min }$, minimum distance of the shoreline to the reference line along the 5 years time. It takes a negative value when a failure in the management target occurs. In that case, the random variable $N_{f}$, defined below, takes a non zero value.

- $N_{f}$, number of years in which the management target is not fulfilled. For the strategies that do not contemplate a maintenance program, if a failure occurs during year $j$, this value is computed as $5-(j-1)$, because it was observed that the failure remains during the next years.

- $D_{\min }^{\alpha}$, minimum distance of the shoreline to the reference line at stretch $\alpha$ for $\alpha=A, B, C, D$

- $N_{f}^{\alpha}$, number of years in which the management target is not fulfilled at stretch $\alpha$, for $\alpha=A, B, C$,

$D$

- $A_{d r y}^{\alpha}$, minimum area of dry beach during the summer period at stretch $\alpha$, for $\alpha=A, B, C, D$

- $V_{L}^{k}$, volume of sand lost during year $k, k=1, . ., 4$ (only for alternative $A_{1}$ )

- $V_{R}^{k}$, volume of sand to be reallocated after year $k, k=1, \ldots, 4$ (only for alternative $A_{1}$ )

The variables $D_{\min }$ and $N_{f}$, are related to the fulfillment of the management objectives. $D_{\min }^{\alpha}$ and $N_{f}^{\alpha}, \alpha(\alpha=A, B, C, D)$ allow to distinguish the stretches where failures occur. The remaining variables quantify other benefits/adverse effects. Denoting by $V^{A_{m}}$ any of these variables, after measuring that quantity for each $y_{q}(x)(q=1, \ldots, Q)$, a sample $\left\{v_{q}^{A_{m}}\right\}_{q=1}^{Q}$ of the r. v. $V^{A_{m}}$ is obtained. This sample can then be used to estimate, among others, the probability density functions of $V^{A_{m}}$, its mean values and standard deviation.

These r.v. were also used to study the performance of the alternatives in economic terms. With that purpose, the following three variables that represent the benefits for the main interest groups, were considered for its use with the multicriteria decision method. 
The total amount that visitors spend, $G^{A_{m}}$, was calculated in terms of the yearly average number of tourist that stay more than one day, one day excursionists and their corresponding average expenditures per trip. They were all assumed to arrive during the summer vacations period, than in Spain can be considered July and August. The first group was distributed uniformly along the whole period while excursionists were assumed to arrive uniformly during the weekends. These numbers were estimated, based on the mean values of data from the period 2004-2009, as a percentage (31.3\%) of values for the Costa Tropical (Patronato de Turismo, 2004-2009). The daily number of visitors was limited to the estimated capacity of each stretch. The total amount of money spent in one year was calculated, based on the mean values of expenditures per trip in 2004-2009 (Patronato de Turismo, 2004-2009), which were $56.90 €$ for tourists and $25.93 €$ for one-day excursionists.

To assess the impact that the measures taken to protect the beach have on the prices of Playa Granada houses, a loglinear hedonic price regression (Parsons and Powell, 2001; Palmquist, 2005) was performed based on the attributes in Table 1. Zones 1, 2 and 3 (see Fig. 5) refer to dummy variables that take value 1 if the house is located in the corresponding zone and 0 otherwise. As can be observed, a dummy variable for Zone 4 was not included in the regression since this was regarded as a buffer zone. These variables measure the willingness of buyers to pay a price in consonance with the environmental value of the beach. The analysis allowed to estimate the total added value of the houses due to the quality of the beach after the 5 years period, $P^{A_{m}}$.

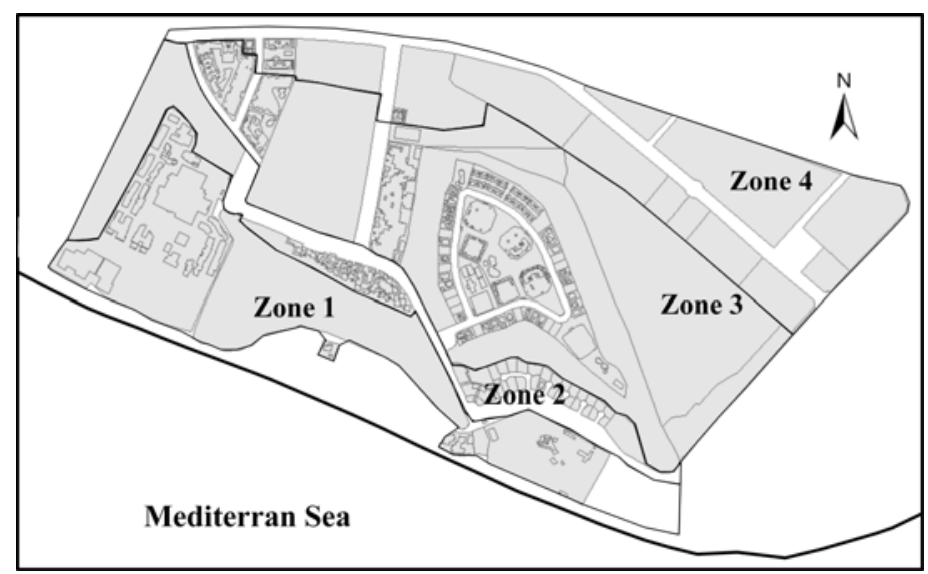

Figure 5. Division into zones for the hedonic price regression analysis.

\begin{tabular}{|lcc|}
\hline $\begin{array}{l}\text { Table 1. Results of the regression analysis. Data source: real } \\
\text { estate prices and structural characteristics provided by the Land } \\
\text { Registry Office of Motril. }\end{array}$ & \\
\hline Variable & Coefficient & Standard Error \\
\hline Constant term, $C_{0}$ & -10.1650 & 1.9314 \\
Living area $\left(\mathrm{m}^{2}\right), \boldsymbol{x}_{\mathbf{1}}$ & 0.8206 & 0.0063 \\
Age of house (years), $\boldsymbol{x}_{\mathbf{2}}$ & 0.0089 & 0.0010 \\
Distance to beachfront $(\mathrm{m}), \boldsymbol{x}_{\mathbf{3}}$ & 0.0003 & 0.0000 \\
Number of storeys, $\boldsymbol{x}_{\mathbf{4}}$ & 0.0005 & 0.0016 \\
Swimming pool, $\boldsymbol{x}_{\mathbf{5}}$ & 0.0233 & 0.0169 \\
Sports court, $\boldsymbol{x}_{\mathbf{6}}$ & 0.0320 & 0.0061 \\
Zone $1, \boldsymbol{z}_{\mathbf{1}}$ & 0.2444 & 0.0616 \\
Zone $2, \boldsymbol{z}_{\mathbf{2}}$ & 0.2099 & 0.0357 \\
Zone 3, $\boldsymbol{z}_{\mathbf{3}}$ & 0.0687 & 0.0088 \\
\hline Number of observations $=1290 ;$ & $\mathrm{R}^{2}=0.95$ & \\
\hline
\end{tabular}


The costs of the works, $C^{A_{m}}$ were calculated, based on the values of the variables obtained from the simulation of the shoreline position and the unit costs. They include:

- an initial cost, $C_{0}$, that depends on the initial volume of sand poured, $V_{P}$, and in the case of $A_{2}$, also on the length of the groins, $L_{G}$. It was assumed that $C_{V_{p}}$, the unit cost of sand poured, was $8 € / \mathrm{m}^{3}$ and that the unit cost per linear meter of groin was $C_{G}=11,500 €$.

- the annual maintenance costs $C_{j}, j=1, . ., 4$, that include a fixed amount, $C_{F i x}$, and in the case of strategy $A_{1}$, also the costs associated with the amounts of sand lost, $V_{L}^{j}$, that have to be poured and the volume of sand to be reallocated, $V_{R}^{j}$. Those values were calculated taking the unit cost of sand to be reallocated, $C_{V_{r}}$, equal to $4 € / \mathrm{m}^{3}$ and a fixed amount per year for beach maintenance $C_{\text {Fix }}=16,020 €$, as estimated by the DGC.

In order to combine the performances into an utility function (a function that globally measures the benefit), for the decision making approach, instead of considering the value of $C^{A_{m}}$, the savings in relation to an upper bound of 150 Million Euros budget, that is, $S^{A_{m}}=15 \cdot 10^{7}-C^{A_{m}}$ were retained.

A large number of simulations, $Q=350$, provided for alternative $A_{m}$ a sample $\left\{\left(g_{q}^{A_{m}}, p_{q}^{A_{m}}, s_{q}^{A_{m}}\right)\right\}_{q=1}^{Q}$ of the random vector $\vec{\xi}^{A_{m}}=\left(G^{A_{m}}, P^{A_{m}}, S^{A_{m}}\right)$. Notice that the first component of $\vec{\xi}^{A_{m}}$ measures the benefits to the local economy, the second one the benefits to local proprietors of houses and the third one the savings for the government, that represent different groups of interests.

\section{Stochastic multi-criteria decision making}

The SMAA-2 (Lahdelma and Salminem, 2001) multi-criteria acceptability analysis combines the components of the random vectors $\vec{\xi}^{A_{n}}, m=1, \ldots, M$, into a utility function that is defined as follows:

$$
u^{A_{m}}\left(\xi^{A_{m}}, \vec{w}\right)=w_{1} G^{A_{m}}+w_{2} P^{A_{m}}+w_{3} S^{A_{m}}
$$

where $\vec{w}=\left(w_{1}, w_{2}, w_{3}\right)$ is a vector that contains non-negative normalized weights, namely, $w_{k} \geq 0$, and $w_{1}+w_{2}+w_{3}=1$. Alternative $A_{i}$ is considered to be better than or equal to alternative $A_{j}$ for given values of $\vec{\xi}^{A_{i}}$ and $\vec{\xi}^{A_{j}}$ and weights $\vec{w}$, if $u^{A_{i}}\left(\vec{\xi}^{A_{j}}, \vec{w}\right) \geq u^{A_{j}}\left(\vec{\xi}^{A_{j}}, \vec{w}\right)$.

The weights represent the preferences of a decision maker. When these preferences are not known, $\vec{w}$ can be assumed to behave as a random vector, whose density function is given by $f_{W}(\vec{w})$. In the application of the multi-criteria decision making method, none of the interest groups preferences was assumed to be more important than others. Accordingly, a uniform joint density function was chosen to characterize the random vector $\vec{w}$ :

$$
f_{W}(\vec{w})=\left\{\begin{array}{ccc}
\frac{1}{\operatorname{vol}(W)} & \text { if } & \vec{w} \in W \\
0 & \text { if } & \vec{w} \notin W
\end{array}\right.
$$

where $\operatorname{vol}(W)$ denotes the volume of $W$, the set of feasible weights.

The method provides, among other descriptors, the acceptability indexes, $a^{A_{m}}$, that describe the share of the parameter values granting alternative $A_{m}$ being selected as the best one and the central weight vector, $\vec{w}^{A_{m}}$, that describes the preferences of a typical decision maker that judges alternative $A_{m}$ as the preferred management strategy.

\section{RESULTS}

Fig. 6 shows examples of shoreline positions after five years that were simulated for all the strategies. The appraisal of the alternatives was first performed in terms of the risk associated with the most representative variables obtained from the simulation. Next, the analysis focused on the multicriteria decision process. 


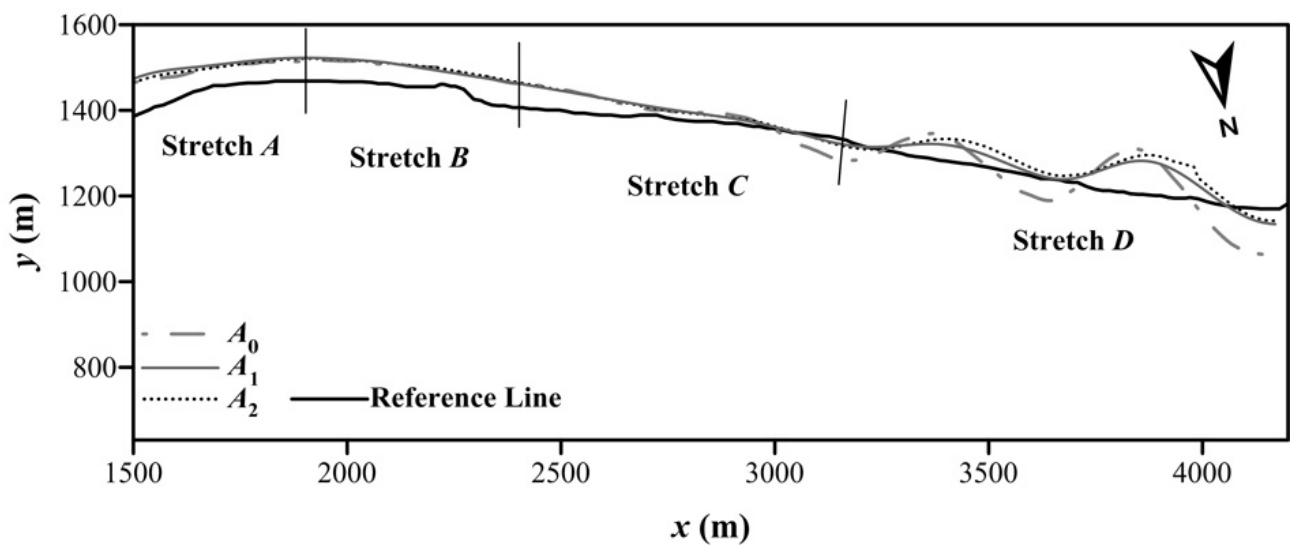

Figure 6. Examples of the shoreline position after the five-year period obtained for all the strategies.

In this context, risk was understood as a probabilistic analysis of the consequences of each alternative. The variables considered were $D_{\min }, N_{f}, D_{\min }^{\alpha}$ and $N_{f}^{\alpha}$. Figs. 7 and 8 show their probability density functions and Table 2 gives their expected values and standard deviations. It also shows the probability of the non-fulfillment of the management target, $p_{f}=\operatorname{Pr}\left(D_{\min } \leq 0\right)$.
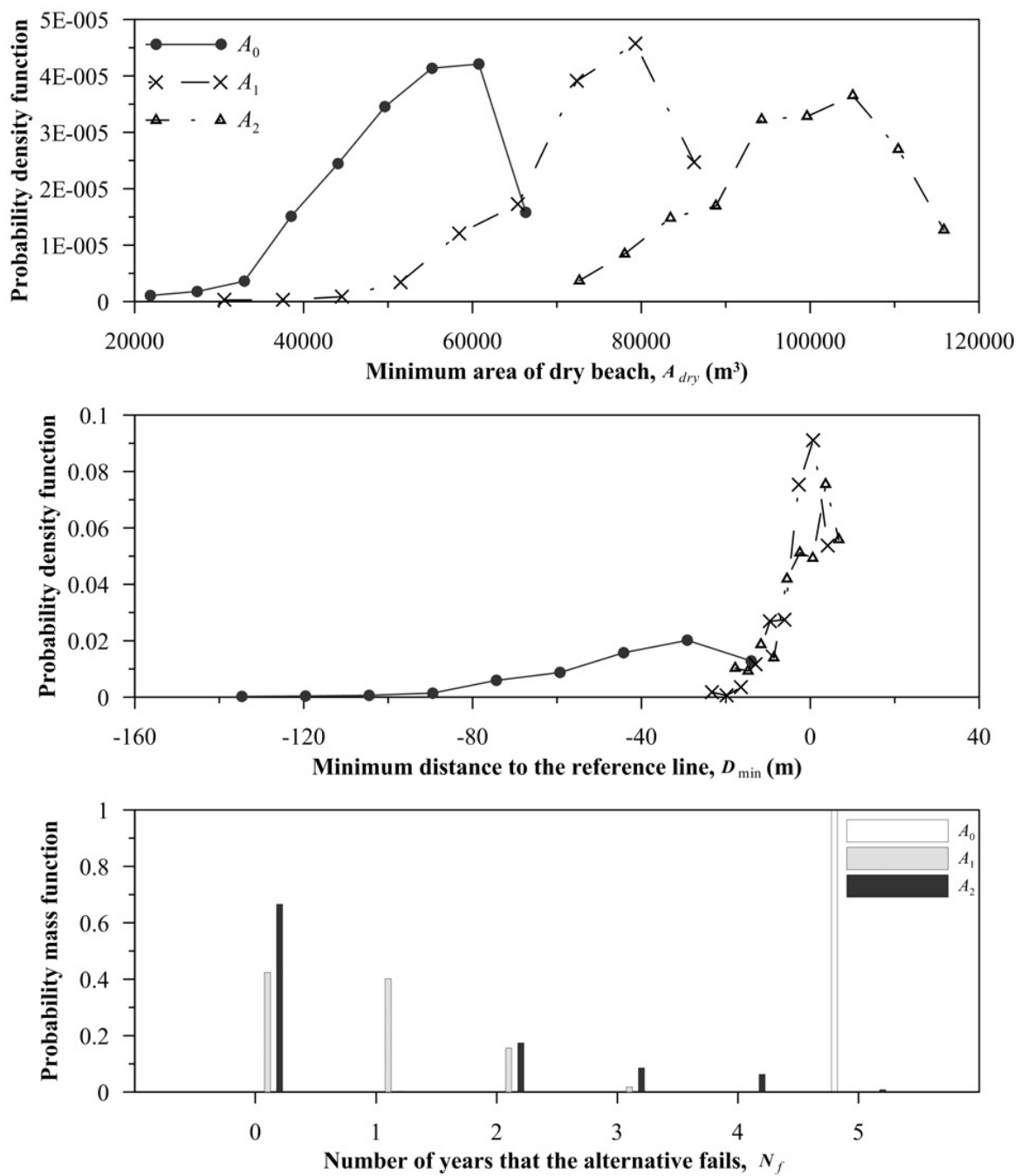

Figure 7. Probability density function of $D_{\min }$ and $A_{\text {dry }}$ and probability mass function of $N_{f}$. 

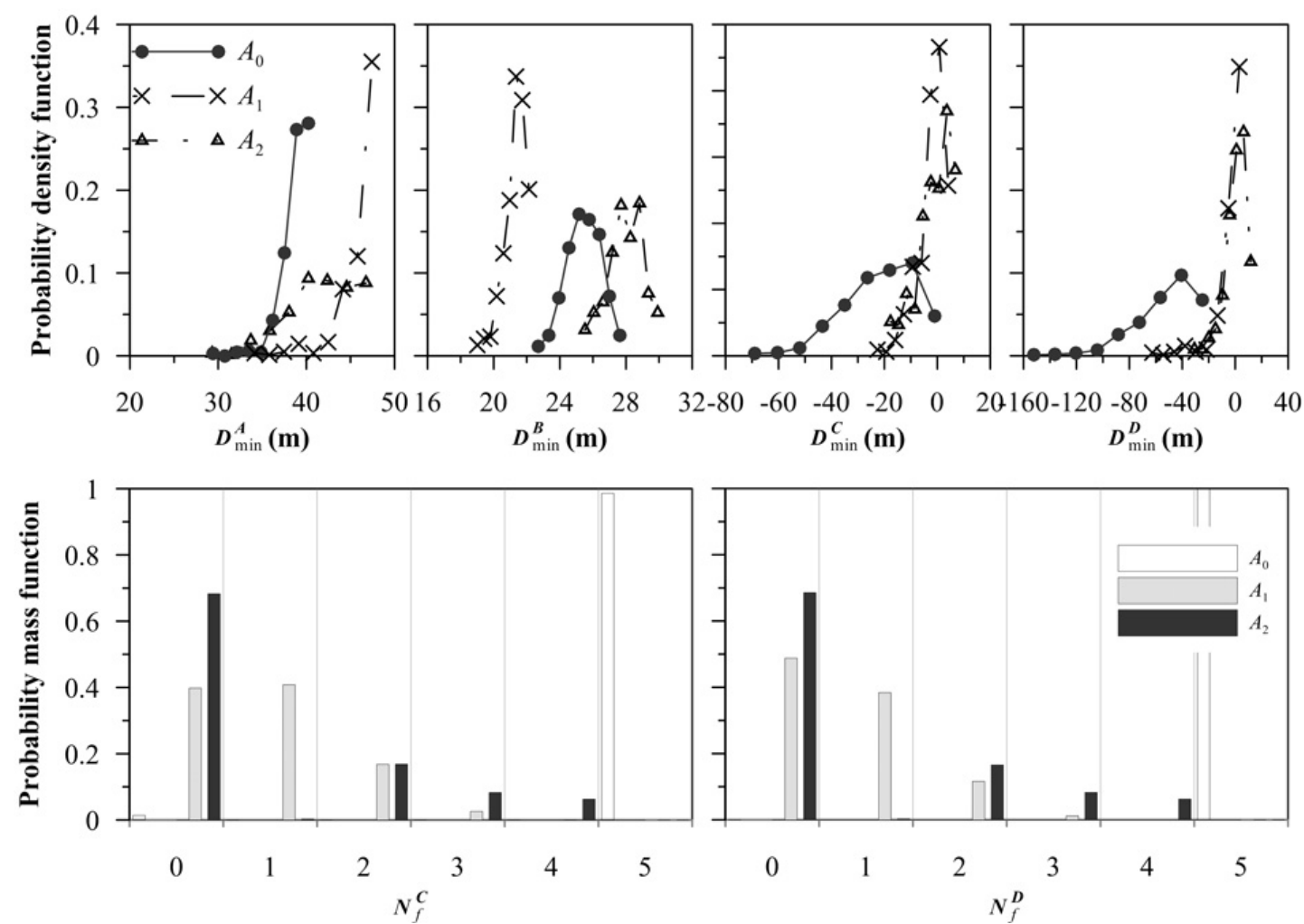

Figure 8. Probability density function of $D_{\min }^{\alpha}$ and probability mass function of $N_{f}^{\alpha}$.

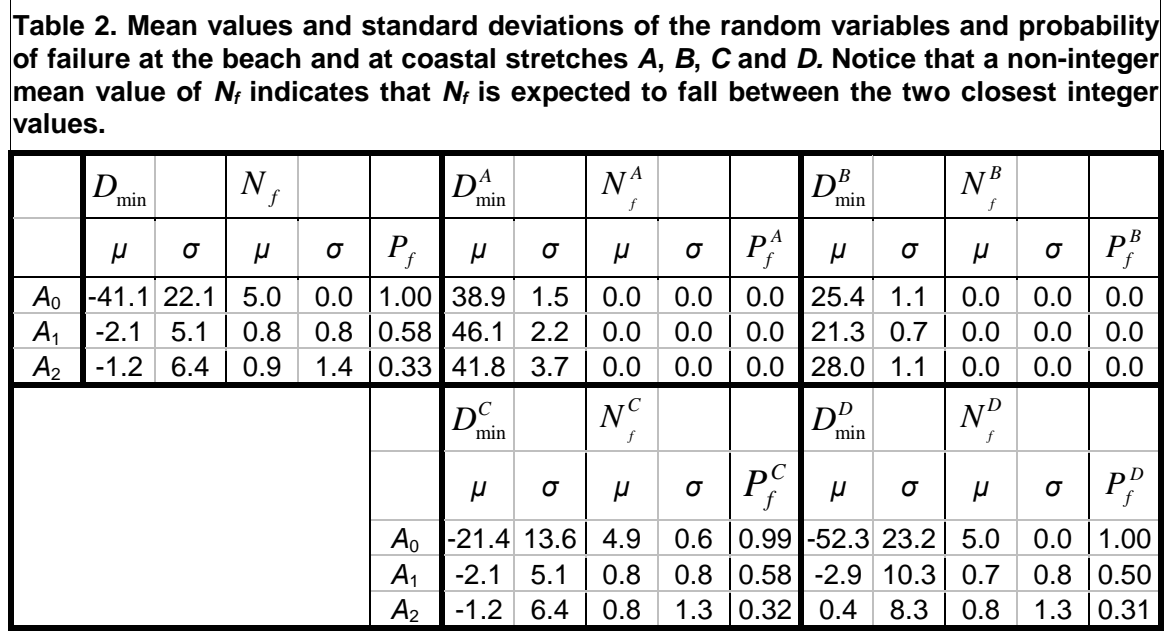

As can be observed in Table 2, the mean values of $D_{\min }$ are all negative. The strategies are thus expected to fail. However, the expected intensity of failure, measured by the absolute value of $D_{\min }$ for negative values, is much higher for the zero alternative, in which no action is taken, and for $A_{1}$. In contrast, this value is lower for alternative $A_{2}$, the strategy that combines beach nourishment with groin construction. Furthermore, its probability of failure is about $1 / 3$, a value considerably lower than the failure probability values for $A_{1}$, which is close to 0.6 , and for $A_{0}$, that is almost certain to fail. Regarding the number of years that the alternatives will fail, there is a very high probability that $A_{0}$ will fail during the entire five-year period whereas $A_{1}$ and $A_{2}$ are expected to fail for only one year.

According to the results obtained in our study, failure is very likely to occur in coastal stretch $D$, whose values are closer to those obtained for the entire beach. Failures were found to be severe for $A_{0}$ (expected $D_{\min }^{D}=-52.3 \mathrm{~m}$ ) with very high standard deviations (approx. $23.2 \mathrm{~m}$ ). These values indicate 
that there is a high probability that the retreat of the shoreline will affect the area protected by the beach. Since this area is the land that has been reclaimed for agriculture, such a retreat would only affect the illegal settlements that will very likely be dismantled anyway in order to restore the wetlands.

If this stretch is excluded from the analysis, the next most vulnerable stretch is $C$. It is very probable that alternatives $A_{1}$ will fail during one year. The failure probability of $A_{2}$ is approximately 0.3. The number of years during which this strategy is expected to fail is between 1 and 2. These failures, however, will not be very serious as they would merely mean a minimum gain in dry beach area which is slightly less than the $10 \mathrm{~m}$ targeted value.

None of the alternatives failed in any of the simulations at stretches $A$ and $B$. The minimum gain in dry beach at $A$ and $B$ was found to be considerably higher than the $10 \mathrm{~m}$ value in all cases. In reference to these stretches, alternative $A_{2}$ was expected to result in a minimum beach width that was slightly smaller than that of $A_{1}$ and also with relatively higher standard deviations.

Fig. 9 represents the density functions of the random variables that measure the economic benefits. Their mean values and standard deviations are given in Table 3, which highlights the best alternative that a stakeholder would select, based only on the criteria that represents his/her interests.
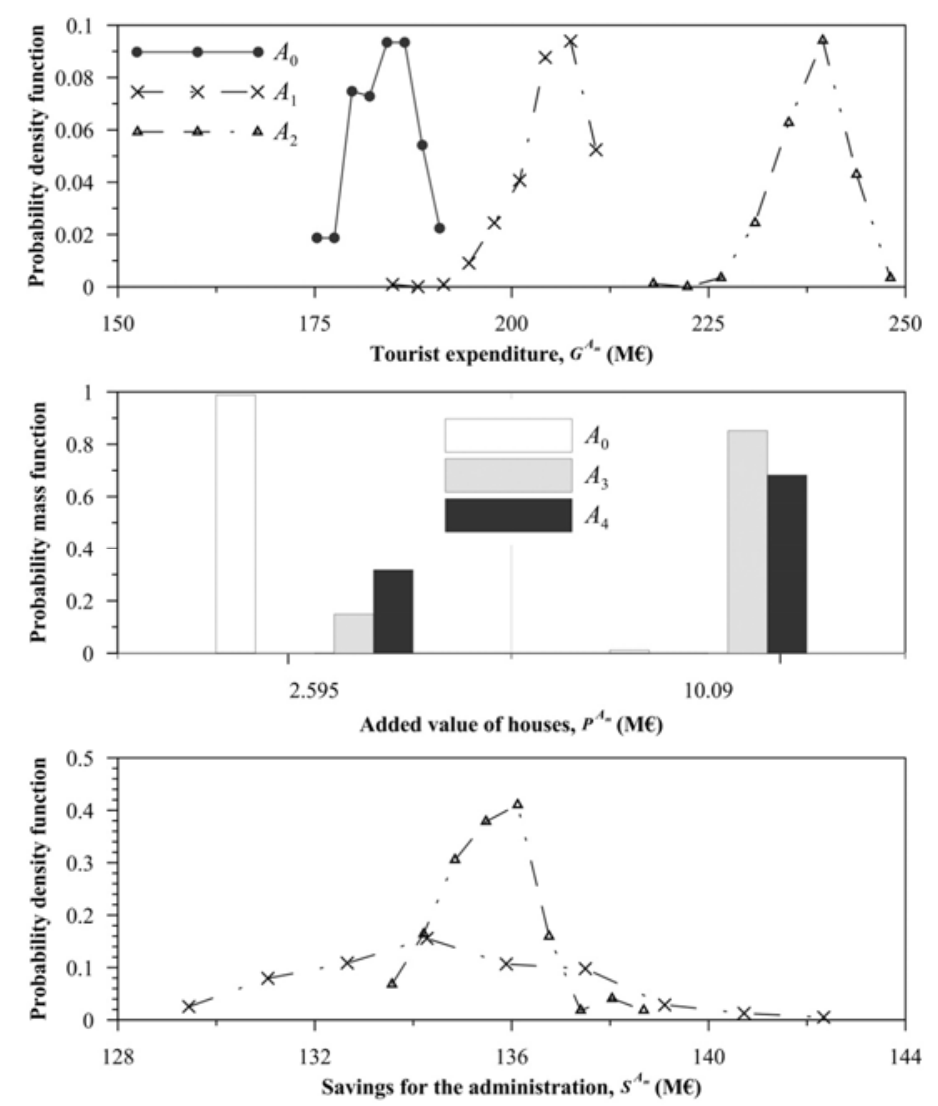

Figure 9. Probability density functions of the random variables that measure the economic benefits

\begin{tabular}{|l|c|c|c|c|c|c|}
\hline \multicolumn{6}{|c|}{ Table 3.Mean values and standard deviations of the economic benefits } \\
\hline & $\mu_{G}$ (M€) & $\sigma_{G}(\mathrm{M} €)$ & $\mu_{P}(\mathrm{M} €)$ & $\sigma_{P}(\mathrm{M} €)$ & $\mu_{S}$ (M€) & $\sigma_{S}$ (M€) \\
\hline$A_{0}$ & 183.8 & 3.8 & 2.7 & 0.9 & 150.0000 & 0.0000 \\
\hline$A_{1}$ & 204.9 & 4.3 & $\mathbf{8 . 9}$ & $\mathbf{2 . 7}$ & 134.6 & 2.6 \\
\hline$A_{2}$ & $\mathbf{2 3 8 . 0}$ & $\mathbf{4 . 3}$ & 7.7 & 3.5 & $\mathbf{1 3 5 . 5}$ & $\mathbf{1 . 0}$ \\
\hline
\end{tabular}

Alternative $A_{2}$ has the highest mean value for $G$ and its standard deviation (approx. $4.32 \mathrm{M€}$ ) is of the same order of magnitude as for $A_{1}$. Therefore, if this were the only variable considered (the one representing the interests of the local population), the most sensible choice would be alternative $A_{2}$. Homeowners, on the other hand, would be more likely to select $A_{1}$, which has the highest expected value with a relatively small variance. In contrast, the administration would be more interested in the 
most economical alternative. Since the preservationist option, $A_{0}$, is not viable, the government's choice would be alternative $A_{2}$, the strategy that involves beach nourishment combined with the construction of groins.

These discrepancies among interest group preferences reflect the advisability of using multicriteria analysis to obtain a compromise solution.

Fig. 10 shows the results of the comparison of the alternatives with the SMAA-2 method. The most acceptable alternative with the highest acceptability index ( $a^{A_{m}}=0.57$ ) was found to be $A_{2}$. Its corresponding central weight vector is $\vec{w}=(0.3817160 .3329650 .285319)$. This means that a typical decision maker supporting alternative $A_{2}$ would give relatively similar weights to all the criteria. Decision makers that selected $A_{1}$ as the best alternative would also give similar weights to the three criteria. As expected, the preservationist alternative obtained a very low acceptability index and a typical decision maker in favor of this alternative would be biased against two interest groups.

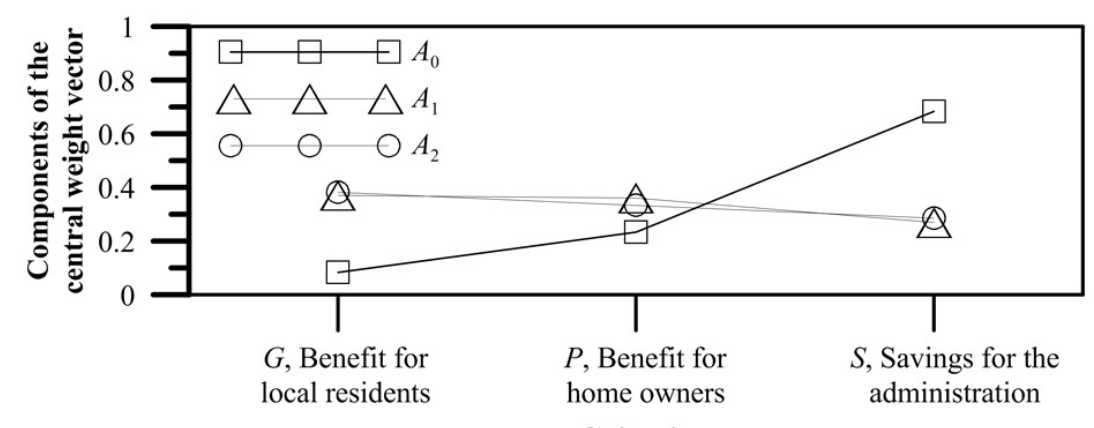

Criteria

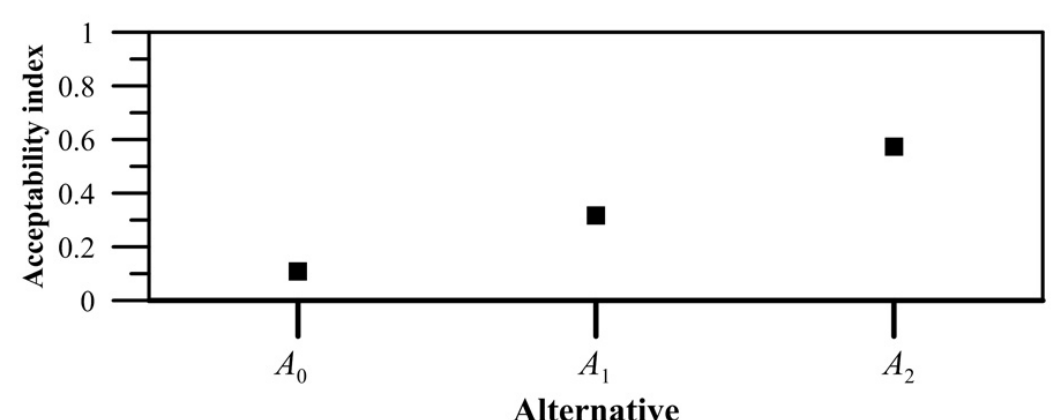

Figure 10. Results of the comparison of the alternatives with the SMAA-2 model.

\section{CONCLUSIONS}

This work applies the methodology for the management of a coastal stretch proposed by Félix et al. (2012) to Playa Granada (Spain), a beach located in the Guadalfeo river delta that is suffering severe erosion problems since the construction of a dam in the watershed. A five years period is considered. It is defined as a management target to offer a minimum beach width during the summer. Three different alternatives are designed for the analysis. Among them, one consisting in no taking any action is also considered.

The assessment of uncertainty in the effect that the implementation of the strategies have on the shoreline evolution is done following the methodology by Baquerizo and Losada (2008) with a oneline model with time dependent boundary conditions (Payo et al. 2002) coupled with a river model that allows to include the effect of regulatory activities at Rules dam (Ávila, 2007).

The shoreline position provided by the morphodynamic model is used to evaluate the performance of the different alternatives in relation to the management target and also in terms of a random vector which components represent the economic benefit for local residents, for house proprietors and for the administration.

A traditional risk analysis of performance of the alternatives reveals the convenience of adopting a multi-criteria analysis that takes into account the random character of the system. The stochastic multi- 
criteria acceptability method, fed with the probability density functions of those random vectors, are then used to rank strategies, providing at the same time the relative importance given to each criterion.

It is found that the best alternative is the one that consists in the construction of a series of groins almost perpendicular to the coast and the nourishment of the beach. The selection of that alternative would not imply to have biased preferences for any of the stake holders as it would be ranked the first giving similar weights to the three economic criteria.

\section{ACKNOWLEDGMENTS}

The work done by the first author was funded by the Consejo Nacional de Ciencia y Tecnología (CONACYT, México). The research of the other authors was carried out within the framework of the research project, Influencia de los procesos litorales multiescala en la gestión costera (TEP-4630), funded by the Regional Government of Andalusia.

\section{REFERENCES}

Ávila, A. 2007. Procesos de múltiple escala en la evolución de la línea de costa. PhD Thesis. Universidad de Granada, Spain. 161 pp.

Baquerizo, A. and M. A. Losada. 2008. Human interaction with large scale coastal morphological evolution. an assessment of the ucertainty. Coastal Engineering, Vol. 55, pp. 556-580.

Dean, R. G. and R. A. Dalrymple. 2004. Coastal Processes with Engineering Applications. Cambridge University Press, Cambridge.

Exceltur, 2005. Resumen Ejecutivo - Impactos sobre el entorno, la economía y el empleo de los distintos modelos de desarrollo turístico del litoral mediterráneo Español, Belares y Canarias. Deloitte - $\quad$ Exceltur (http://www.exceltur.org/excel01/contenido/portal/encuentro /Sumario_residencial_completo.pdf)

Félix, A., A. Baquerizo, J.M. Santiago and M. A. Losada (2012). Coastal zone management with stochastic multi-criteria analysis. Journal of Environmental Management, 112, 252-266.

Junta de Andalucía. 2006. Decreto 59/3006 de 14 de marzo por el que se acuerda la formulación del Plan de Ordenación del Territorio del Litoral de Granada. Consejería de Obras Públicas y Transporte.

Lahdelma, R. and P. Salminen. 2001. Smaa-2: Stochastic Multicriteria Acceptability Analysis for Group Decision Making. Operations Research, 49(3):444-454.

La Caixa, 2010. Anuario Económico de España 2010.

Losada M. A., A. Baquerizo, M. Ortega-Sánchez and A. Ávila. 2011. Coastal evolution, sea level and assessment of intrinsic uncertainty. Journal of Coastal Research. Special Issue, No. 59, pp. 218228. Proceedings of the Nicholas C. Kraus Honorary Symposium.

Losada M. A. 2012. Las Riberas del Mar Océano (The ocean and sea shores of Spain). Scripts and DVDs of the RTVE series, pp 170, Bilingual edition. Ed. M.A. Losada, Universidad de Granada.

Patronato de Turismo. 2004-2009. Memorias 2004-2009. Observatorio turístico de la Provincia de Granada

Palmquist, R. B. 2005. Property value models. In Handbook of Environmental Economics, Vol. 2, ELSEVIER, Netherlands, pp. 763-819.

Parsons, G. and M. Powell. 2001. Measuring the Cost of Beach Retreat. Coastal Management, Vol. 29, pp. 91-131.

Payo A., A. Baquerizo and M. A. Losada. 2002. One-line model with time dependent boundary conditions. Proc. 28th Coastal Engineering Conf., ASCE, World Scientific, Vol. 3, pp 30463052.

Santiago, J. 2006. Evolución Ambiental y Socioeconómica como Fundamento de la Ordenación Litoral, PhD thesis, Universidad de Granada, Spain. 259 pp. In Spanish.

Stynes, D.J. 1997. Economic impacts of Tourism: A handbook for tourism professionals. Urbana, IL: University of Illinois. Tourism Research Laboratory. 